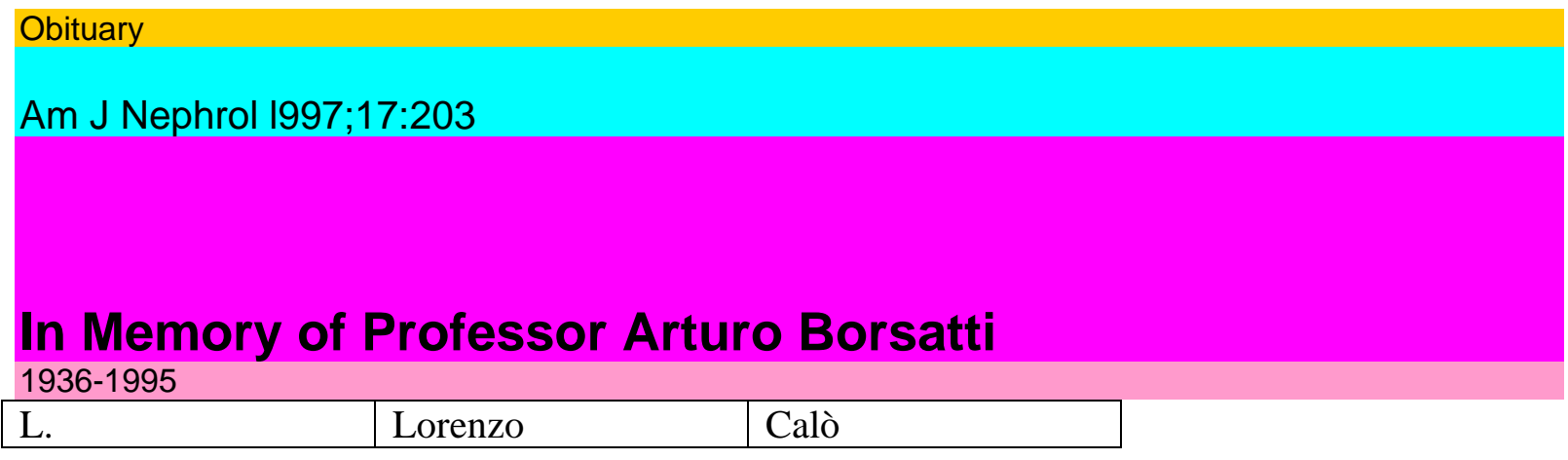

Division of Nephrology, University of Padua, Italy

\title{
Arturo Borsatti
}

It is for me a great honor to have the possibility to remember, even in a few words, my maestro and friend Professor Arturo Borsatti, Chief of the Nephrology Clinic and Dean of the Medical School at the University of Padua, who died prematurely last year, and to whose memory this session of the Congress is dedicated.

I think the best way to remember him is not by talking about his many and important scientific contributions but to highlight his humane qualities: caring, kindness, and honesty, which made Arturo Borsatti so much appreciated by us, his collaborators and students. Even during his extremely busy deanship, all the students of the Medical School were keenly aware of his being always available to listen, counsel, empathize, and solve problems. It is well known, in fact, that he accepted the position of Dean not for obtaining personal privilege but, as he said: 'To be useful to my university.'

I would like to mention on this occasion the passion he showed in contributing to the birth of the International Association for the History of Nephrology, answering the call from Natale De Santo with several contributions from the University of Padua and from his own group at the First International Conference on the History of Nephrology held in Naples, in October of 1993. Arturo Borsatti is remembered by everyone at the Medical School of Padua for the imprint he left on their life. It is a distinct privilege for me to have grown with him not only because of what I learned from him but also for the opportunity it provided to develop an esteem for the qualities he embodied.

I personally prefer to remember my maestro in the image of the olive tree, so common in the south of Italy where I was born, a big and productive tree which, however, filters the light that illuminates us all.

\section{KAÏUiEH}

E-Mail karger@karger.ch Fax + 41613061234

http://www. karger. ch

(C) 1997 S.KargerAG, Basel

203 